\title{
PERBANDINGAN KADAR ASPAL HASIL EKTRAKSI PADA CAMPURAN ASPAL AC-BC
}

\author{
Fitridawati Soehardi ${ }^{1}$ \\ ${ }^{1)}$ Program Studi Teknik Sipil, Fakultas Teknik, Universitas Lancang Kuning \\ Jl. Yos Sudarso Km 8 Rumbai-Pekanbaru, \\ email: fitridawati@unilak.ac.id
}

\begin{abstract}
The purpose of this study is the comparison of asphalt content of extracted results on the mixture $(A C-B C)$ in accordance with the 2010 revision of the reflex 3 . The method used in this study by extraction using a centrifuge extractor on three specimens of test specimens derived from AMP, The asphalt finisher blend of asphalt from the back of the Asphalt Finisher machine and the compaction result taken using Coredrill using a pertaline solvent. This research includes testing of asphalt content before and after Ektraksi. Based on the results of research The percentage of asphalt extraction results from the 6 test objects from each sample obtained the average value of AMP, finisher, and coredrill is 5.60\%, 5.58\%, 5.49\%. Based on the results of the study Comparison of extraction rate by using a solvent of pertalite, from extraction test of Asphalt Mixing Plant asphalt content, Asphalt Finisher, Coredrill asphalt value decreasing from JMF. So that can be made formulation KA Job Mix Formula $(J M F)=$ $K A$ Asphalt Mixing Plant $(A M P)>K A$ when overlaying $>K A$ core. Average: $5.60 \% \geqq 5.60 \%>$ $5.58 \%>5.49 \%$. The extraction results are far from the minimum tolerance threshold of the mixture according to Binamarga 20102010 revision 3 (three) specifications. Therefore, this study may also support the statement on the Binamarga 2010 revision 3 (three) specification which states core test should not be used for extraction testing.
\end{abstract}

Keywords : bitumen content, extraction, centrifuge

\begin{abstract}
Abstrak: Tujuan dari penelitian ini adalah perbandingan kadar aspal hasil ektraksi pada campuran (AC-BC) sesuai dengan speksifikasi 2010 revisi 3. Metode yang digunakan pada penelitian ini dengan cara ektraksi menggunakan alat centrifuge extractor pada tiga benda uji yaitu benda uji yang berasal dari AMP, campuran aspal yg berasal dari belakang mesin Asphalt Finisher dan hasil pemadatan yang diambil menggunakan Coredrill dengan menggunakan pelarut pertaline. Penelitian ini meliputi pengujian kadar aspal sebelum dan sesudah Ektraksi. Berdasarkan hasil penelitian Persentase hasil ekstraksi kadar aspal dari ke 6 benda uji dari masing-masing sampel didapat nilai rata- rata yaitu dari AMP, finisher,dan coredrill adalah $5,60 \%, 5,58 \%, 5,49 \%$. Berdasarkan hasil penelitian Perbandingan kadar hasil ekstraksi dengan menggunakan pelarut pertalite, dari pengujian ekstraksi kadar aspal Asphalt Mixing Plant, Asphalt Finisher, Coredrill nilai aspal semakin berkurang dari JMF. Sehingga dapat dibuat rumusan $\quad K A$ Job mix Formula $(J M F)=K A$ Asphalt Mixing Plant $(A M P)>$ KA saat penghamparan $>K A$ core. Rata - rata : $5,60 \% \geqq 5,60 \%>5,58 \%>$ $5,49 \%$. hasil ekstraksi jauh dari ambang batas minimum toleransi campuran menurut spesifikasi Binamarga 2010 revisi 3(tiga). Maka dari itu penelitian ini juga dapat mendukung pernyataan pada spesifikasi Binamarga 2010 revisi 3(tiga) yang menyebutkan uji inti (core) tidak boleh digunakan untuk pengujian ekstraksi.
\end{abstract}

Kata kunci : kadar aspal, ektraksi, sentrifuge. 
Infrastruktur jalan mempunyai fungsi yang sangat penting dalam perkembangan suatu daerah. Jalan merupakan sarana penghubung antar daerah yang dipergunakan oleh masyarakat umum sebagai prasarana transportasi. Sehingga diperlukan struktur perkerasan jalan yang baik dan mempunyai kualitas pekerjaan sesuai umur rencana.

Pada proses pelaksanaan pembangunan kontruksi jalan. Pihak pelaksana pekerjaan dan konsultan pengawas yang ditunjuk oleh pihak pemilik pekerjaan untuk melaksanakan pekerjaan berdasarkan kontrak, dan melakukan pekerjaannya sesuai dengan spesifikasi umum yang dikeluarkanoleh kementrian pekerjaan umum, Direktorat Jendal Bina Marga.

Setelah dikeluarkannya Surat Edaran Direktorat Jenderal Bina Marga No.17/SE/Db/2012 tanggal 21 November 2012 perihal penyampaian buku dokumen pengadaan pekerjaan fisik spesifikasi umum 2010 (revisi 2) untuk pekerjaan konstruksi (pemborongan) jalan dan jembatan. Terdapat perbedaan antara spesifikasi umum Bina Marga tahun 2006 dengan spesifikasi binamarga tahun 2010 revisi 2 (dua) yaitu dalam segi pembayaran. Namun dalam perjalannya terjadi lagi perubahan pada spesifikasi umum tahun 2010 revisi 2 (dua) yang kemudian diperbarui lagi menjadi spesifikasi umum tahun 2010 revisi 3 (tiga) yang hingga sekarang dipergunakan.

Pada spesifikasi umum 2010 revisi 3 (tiga) sistem pembayaran aspal terpisah antara aspal dan agregat. Dalam spesifikasi umum tahun 2010 revisi 3 (tiga) subbab 6.3.7 poin $3 \mathrm{~d}$ mengenai pengendalian mutu dan pemeriksaan dilapangan, disebutkan bahwa benda uji inti (core) tidak boleh digunakan untuk pengujian ekstraksi, uji ekstraksi harus dilakukan menggunakan benda uji campuran beraspal gembur yang diambil dibelakang mesin penghampar. Hal ini menimbulkan keresahan dari pihak pelaksana kegiatan (kontraktor) karena selalu terjadi kehilangan kadar aspal dari nilai Job Mix Formula (JMF) setelah dilakukan pengujian ekstraksi menggunakan alat extractor, sehingga menjadi permasalahan bagi pihak yang berkepentingan.

Berdasarkan spesifikasi umum 2010 revisi 3 (tiga) telah diisyaratkan bahwa toleransi kadar aspal adalah $\pm 0,3 \%$ dari berat total campuran. Hal ini mengindikasi bahwa kadar aspal sangat berpengaruh besar terhadap umur pelayanan lapis perkerasan jalan.

Berdasarkan kondisi tersebut perlu dilakukan penelitian terhadap hasil uji ekstraksi campuran aspal AC-BC untuk mengetahui penyebab terjadinya kehilangan kadar aspal hasil ekstraksi dari campuran aspal AC-BC dengan menggunakan benda uji yang berasal dari instalasi pencampur aspal (asphalt mixing plant), saat penghamparan (dibelakang asphalt finisher), dan setelah pemadatan lapangan (hasil core). Sehingga dapat diketahui dimana dan penyebab terjadi kehilangan aspal yang cukup besar. Hal ini penting bagi pelaksana dilapangan dan owner dalam mengambil keputusan terhadap segi 
pembayaran pekerjaan.

\section{KAJIAN PUSTAKA}

Lapis Aspal Beton adalah lapisan penutup konstruksi perkerasan jalan yang mempunyai nilai struktural yang pertama kali dikembangkan di Amerika oleh The Asphalt Institute dengan nama Asphalt Concrete (AC). Menurut Bina Marga Departemen Pekerjaan Umum, campuran ini terdiri atas agregat bergradasi menerus dengan aspal keras, dicampur, dihamparkan dan dipadatkan dalam keadaan panas pada suhu tertentu..

\section{Bahan Campuran Aspal}

Menurut Manual Campuran Beraspal Panas, campuran beraspal adalah suatu kombinasi campuran antara agregat dan aspal. Dalam campuran beraspal, aspal berperan sebagai pengikat atau lem antar partikel agregat, dan agregat berperan sebagai tulangan.

\section{Agregat}

Agregat merupakan komponen utama dari lapisan perkerasan jalan yaitu mengandung $90 \% \quad-\quad 95 \%$ agregat berdasarkan persentase berat atau $75 \%-85 \%$ agregat berdasarkan persentase volume (Sukirman, 1999).

\section{Filler}

Filler adalah bahan berbutir halus yang mempunyai fungsi sebagai pengisi pada pembuatan campuran aspal. Filler didefinisikan sebagai fraksi debu mineral lolos saringan no. $200(0,074 \mathrm{~mm})$ bisa berupa kapur, debu batu, atau bahan lain, dan harus dalam keadaan kering (kadar air maksimal 1\%).

\section{Aspal}

Aspal yang dipergunakan sebagai material perkerasan jalan berfungsi sebagaiberikut :

1. Bahan pengikat, memberikan ikatan yang kuat antara aspal dan agregat dan sesama aspal.

2. Bahan pengisi, mengisi rongga antar butir agregat dan pori-pori yang ada dalam butir agregat itu sendiri.

Fungsi utama aspal untuk kedua jenis proses pembentukan perkerasan yaitu proses pencampuran prahampar dan pascahampar itu berbeda. Pada proses prahampar aspal yang dicampur dengan agregat akan membungkus atau menyelimuti butir-butir agregat, mengisi pori antar butir, dan meresap kedalam pori masing-masing butir. Pada proses pascahampar aspal mengisi pori-pori lapisan agregat (Sukirman, 2003).

\section{Ekstraksi}

Proses ekstraksi merupakan proses pemisahan campuran dua atau lebih bahan dengan cara menambahkan pelarut yang bisa melarutkan salah satu bahan yang ada dalam campuran tersebut dapat dipisahkan.

Rumus untuk menentukan kadar aspal hasil ekstraksi adalah sebagai berikut :

$$
\mathrm{H}=(\mathrm{A}-(\mathrm{E}+\mathrm{D}) / \mathrm{A} \times 100 \%
$$

Keterangan :

$\mathrm{H}=$ kadar aspal sampel (\%)

A = Berat Sampel sebelum ekstraksi (gram)

$\mathrm{D}=$ Berat masa dari kertas filter (gram)

$\mathrm{E}=$ Berat sampel setelah ekstraksi (gram). 


\section{Metode pengambilan populasi dan Sampel}

Populasi merupakan objek atau subjek yang berada pada suatu wilayah dan memenuhi syarat-syarat tertentu berkaitan dengan masalah penelitian. (Riduwan,2004).

Sample adalah bagian dari populasi yang mempunyai ciri-ciri atau keadaan tertentu yang akan diteliti. Karena tidak semua data dan informasi akan diperoses dan tidak semua orang atau benda akan diteliti melaikan cukup dengan menggunakan sampel yang mewakilinya. Hal ini harus representatif disamping itu peneliti wajib mengerti tentang besar ukuran sample, teknik sampling dan karakteristik populasi dalam sampel. (Riduwan,2004).

Teknik pengambilan sampel menggunakan rumus Taro Yamane yang dikutip oleh Riduwan (2004:65) sebagai berikut:

$$
\mathrm{n}=\frac{N}{N d^{2}+1}
$$

Keterangan:

$\mathrm{n} \quad=$ Jumlah Sampel

$\mathrm{N}=$ Jumlah Populasi

$\boldsymbol{d}^{\mathbf{2}}=$ Presisi yang ditetapkan

\section{METODE PENELITIAN}

Penelitian ini menggunakan metode percobaan laboratorium. Penelitian ini bertujuan untuk mengetahui hasil perbandingan kadar aspal hasil ektraksi campuran AC-BC antar Job Mix Formula dengan benda uji hasil pencampur aspal (asphalt mixing plant), saat penghamparan (dibelakang asphalt finisher), dan setelah pemadatan lapangan (hasil core).

\section{Bahan penelitian.}

Material yang akan digunakan dalam penelitian ini adalah :

1. Agregat gradasi kasar dari Hot bin yang berasal dari quarry Bangkinang

2. Campuran aspal dari asphalt mixing plant (AMP).

3. Campuran aspal yang diambil dari belakang Asphalt Finisher.

4. Benda uji hasil (hasil core).

5. Pertaline.

\section{Peralatan pengujian}

Peralatan pengujian Ektraksi kadar aspal. Pengujian ini memakai standar SNI 036894-2002. Adapun alat untuk pengujian ektraksi kadar aspal yang dipakai adalah:

1. Alat Centrifuge Extractor yang dilengkapi cawan, dengan putaran bervariasi hingga 3600 rpm (SNI-036894-2002).

2. Gelas ukur $500 \mathrm{ml}$.

3. Saringan Ekstraksi atau Kertas filter.

4. Timbangan kapasitas $5 \mathrm{~kg}$.

5. Oven.

6. Baskom.

\section{Pembuatan Benda uji}

Jumlah Benda uji

Benda uji yang dipergunakan dalam penelitian ini berjumlah 3 buah yang berasal dari hasil pencampur aspal (asphalt mixing plant), saat penghamparan (dibelakang asphalt finisher), dan setelah pemadatan 
lapangan (hasil core). Pengambilan benda uji sesuai dengan Standar Nasional Indonesia SNI 03-6889-2002 tentang Tata Cara Pengambilan Contoh Agregat.

\section{Pembuatan Benda uji}

Pembuatan sampel menggunakan benda uji yang berasal dari hasil pencampur aspal (asphalt mixing plant), saat penghamparan (dibelakang asphalt finisher), dan setelah pemadatan lapangan (hasil core). Kemudian dibuat sampel bedasarkan kebutuhan penelitian antara lain sebagai berikut:

Sample 1 adalah campuran AC-BC yang diambil dari truk penampung setelah campuran aspal selesai diolah di Asphalt Mixing Plant (AMP). Berat campuran yang diambil adalah seukuran sekop atau kira-kira 7 kilogram dengan jumlah benda uji yang akan diekstraksi sebanyak \pm 6 populasi untuk @ \pm 1200 gram ekstraksi (sesuai kapasitas alat ekstraksi sentrifus. Sesuai dengan persamaan 2 dengan presisi yang ditetapkan $5 \%$ diperoleh benda uji yang digunakan adalah 6 buah.

Sample 2 adalah campuran AC-BC yang diambil dari belakang asphalt finisher saat aspal dihamparkan di lokasi kegiatan. Berat campuran yang diambil adalah seukuran sekop atau kira-kira 7 kilogram dengan jumlah benda uji yang akan diekstraksi sebanyak \pm 6 populasi untuk@ $@$ 1200 gram ekstraksi. Sesuai dengan persamaan 2 dengan presisi yang ditetapkan $5 \%$ diperoleh benda uji yang digunakan adalah 6 buah.

Sample 3 adalah campuran AC-BC yang sudah dipadatkan dengan menggunakan alat core drill. Jumlah benda uji yang diambil adalah 6 buah sesuai spesifikasi umum Bina Marga 2010 revisi 3(tiga) yang menyebutkan bahwa benda uji hasil (core drill) diambil sebanyak 6 buah untuk setiap 200 meter panjang. Sesuai dengan persamaan 2 dengan presisi yang ditetapkan 5\% diperoleh benda uji yang digunakan adalah 6 buah dengan berat total adalah 4,51 kilogram.

\section{Pengujian bahan}

Pengujian Bahan pada Penelitian ini dilakukan di laboratorium PT. Hasrat Tata Jaya yang terletak di Kecamatan Bangkinang Seberang, Kabupaten Kampar, Provinsi Riau.

Prosedur pengujian ekstraksi campuran aspal (SNI - 03-6894-2002) dilaksanakan dengan cara sebagai berikut :

1. Menimbang sampel dan saringan ekstraksi sebelum melakukan ekstraksi aspal.

2. Kemudian sampel dimasukkan kedalam mesin ekstraksi dan direndam dengan Bensin sampai sampel benar-benar bersih dari aspal.

3. Selama mesin ekstraksi membersihkan aspal dari campuran beraspal dengan cara memisahkan aspal yang kemudin dialirkan dengan selang keluar.

4. Bensin yang terakhir dikeluarkan yang sudah bersih atau jenuh ditadah di gelas ukur untuk digunakan pada sampel berikutnya. 
5. Setelah selesai lalu mengeluarkan sampel hingga bensinnya melayang atau habis.

6. Setelah itu didiamkan sampai dingin, lalu ditimbang beserta wadahnya.

7. Menghitung nilai kadar aspal.

8. Mengulangi prosedur tersebut untuk sampel berikutnya .

Pengujian dilakukan pada benda uji :

1. Ekstraksi kadar aspal dari mix design (dari AMP).

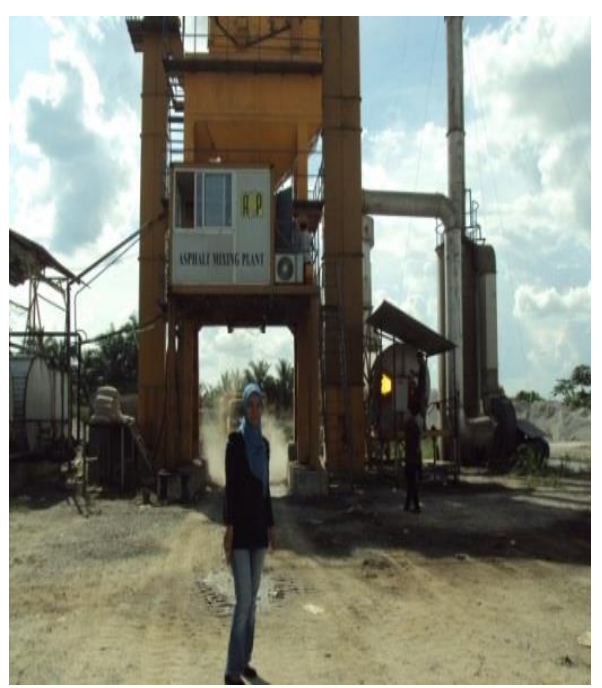

Gambar 1. Asphalt Mixing Plant PT. Hasrat Tata Jaya

2. Ekstraksi kadar aspal dari benda uji yang diambil dari belakang mesin penghampar.

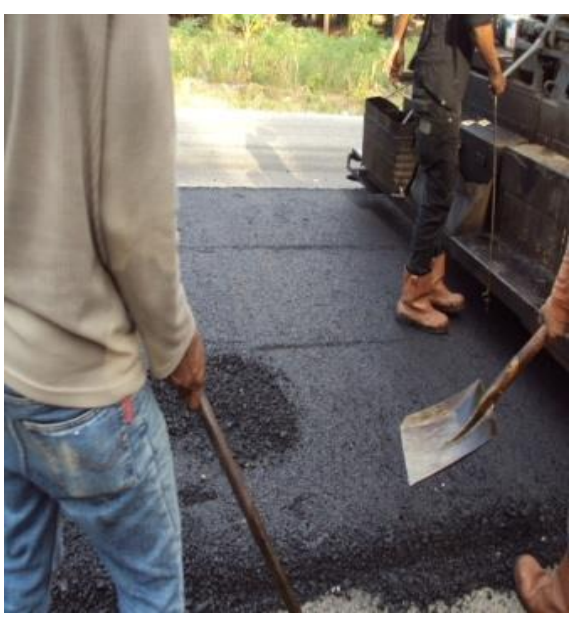

Gambar 2. Pengambilan Sampel Dari Asphalt Finisher
3. Ekstraksi kadar aspal dari benda uji hasil (core drill).

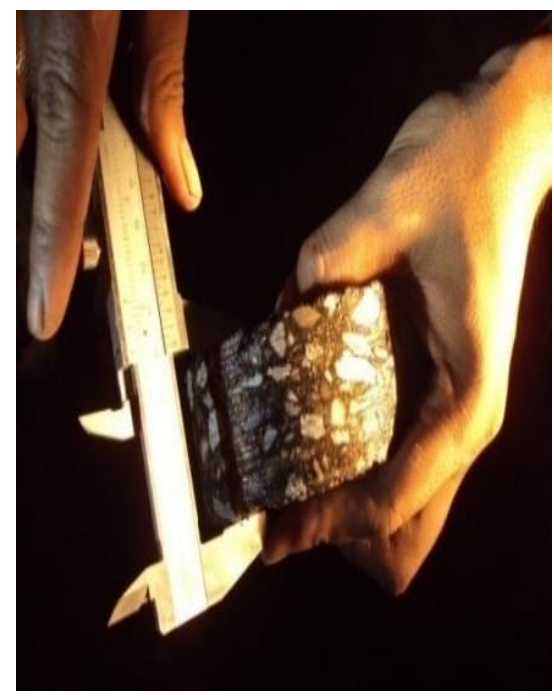

Gambar 3. Contoh Pengambilan benda uji hasil (core drill)

\section{HASIL DAN PEMBAHASAN}

\section{Hasil Pengujian Ekstraksi Dari Benda}

\section{Uji Yang Diambil Dari AMP}

Data hasil pengujian ekstraksi kadar aspal dari AMP dapat dilihat pada Tabel 1 .

\section{Tabel 1. Hasil Ekstraksi Kadar Aspal}

\begin{tabular}{ccc} 
No & Benda Uji & $\begin{array}{c}\text { Kadar aspal Hasil } \\
\text { Ekstraksi (\%) }\end{array}$ \\
\hline 1 & Sample -1 & 5.62 \\
\hline 2 & Sample -2 & 5.58 \\
\hline 3 & Sample -3 & 5.60 \\
\hline 4 & Sample -4 & 5.61 \\
\hline 5 & Sample -5 & 5.59 \\
\hline 6 & Sample -6 & 5.60 \\
\hline \multicolumn{2}{c}{ Rata-rata }
\end{tabular}

Sumber: Soehardi (2017)

Grafik kadar aspal hasil ekstraksi dari 6 (enam) sampel dari AMP dapat dilihat pada Gambar 4. 


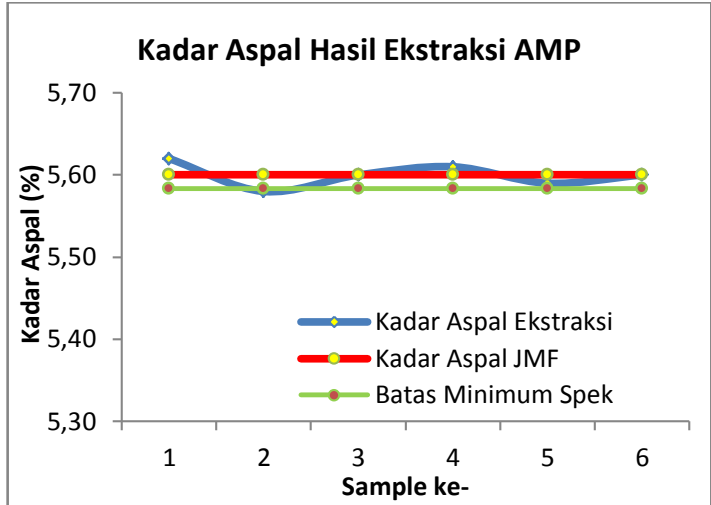

Gambar 4. Kurva kadar aspal saat di Asphalt Mixing Plant (AMP)

Dari Gambar 4 dapat dilihat bahwa kadar aspal hasil ekstraksi dari benda uji dari AMP, ada yang nilainya di bawah dan di atas dari kadar aspal JMF 5,6\%, tetapi masih masuk dalam batas speksifikasi 2010 revisi 3 adalah $\pm 0,3 \%$, dengan nilai rata-rata $5,60 \%$.

\section{Hasil Pengujian Ekstraksi Dari Benda}

\section{Uji Yang Diambil Dari Belakang}

\section{Asphalt Finisher}

Data hasil pengujian ekstraksi kadar aspal dari AMP dapat dilihat pada Tabel 2.

Tabel 2. Hasil Ekstraksi Kadar Aspal (Diambil Dari Belakang Asphalt Finisher)

\begin{tabular}{ccc} 
No & Benda Uji & $\begin{array}{c}\text { Kadar aspal Hasil } \\
\text { Ekstraksi }(\%)\end{array}$ \\
\hline 1 & Sample -1 & 5.60 \\
\hline 2 & Sample -2 & 5.58 \\
\hline 3 & Sample -3 & 5.59 \\
\hline 4 & Sample -4 & 5.56 \\
\hline 5 & Sample -5 & 5.60 \\
\hline 6 & Sample -6 & 5.55 \\
\hline & Rata-rata
\end{tabular}

Sumber: Soehardi (2017)

Grafik kadar aspal hasil ekstraksi dari 6 (enam) sampel dari AMP dapat dilihat pada Gambar 5.

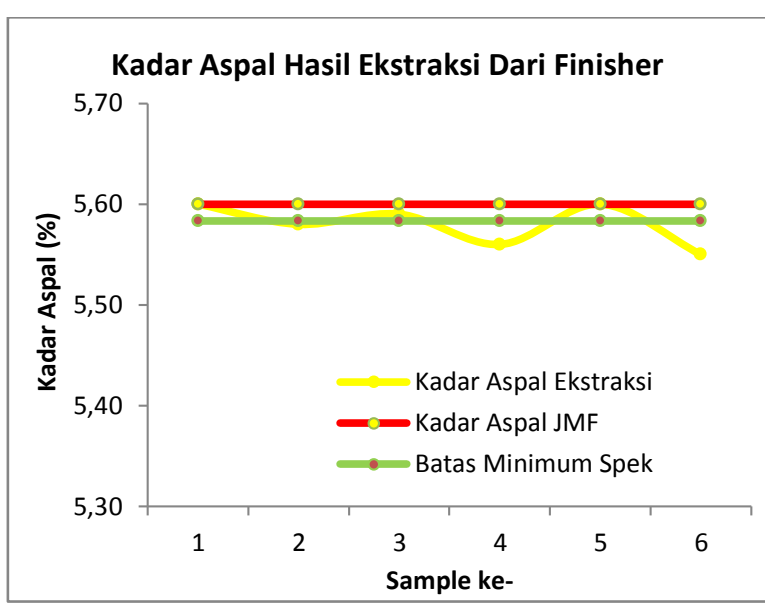

Gambar 5. Kurva kadar aspal saat di Belakang Asphalt Finisher

Dari Gambar 5 dapat dilihat bahwa kadar aspal hasil ekstraksi dari benda uji dari Belakang Asphalt Finisher, ada yang nilainya di bawah dan di atas dari kadar aspal JMF $5,6 \%$, tetapi masih masuk dalam batas speksifikasi 2010 revisi 3 adalah $\pm 0,3 \%$, dengan nilai rata-rata 5,58\%.

\section{Hasil Pengujian Ekstraksi Dari Benda}

\section{Uji Yang Diambil dari hasil Core.}

Data hasil pengujian ekstraksi kadar aspal dari AMP dapat dilihat pada Tabel 3.

Tabel 3. Hasil Ekstraksi Kadar Aspal (Diambil dari hasil Core)

\begin{tabular}{ccc} 
No & Benda Uji & $\begin{array}{c}\text { Kadar aspal Hasil } \\
\text { Ekstraksi }(\%)\end{array}$ \\
\hline 1 & Sample -1 & 5.49 \\
\hline 2 & Sample -2 & 5.50 \\
\hline 3 & Sample -3 & 5.48 \\
\hline 4 & Sample -4 & 5.51 \\
\hline 5 & Sample -5 & 5.49 \\
\hline 6 & Sample -6 & 5.47 \\
\hline & Rata-rata & 5.49 \\
\hline
\end{tabular}

Sumber: Soehardi (2017)

Grafik kadar aspal hasil ekstraksi dari 6 (enam) sampel dari AMP dapat dilihat pada Gambar 6. 


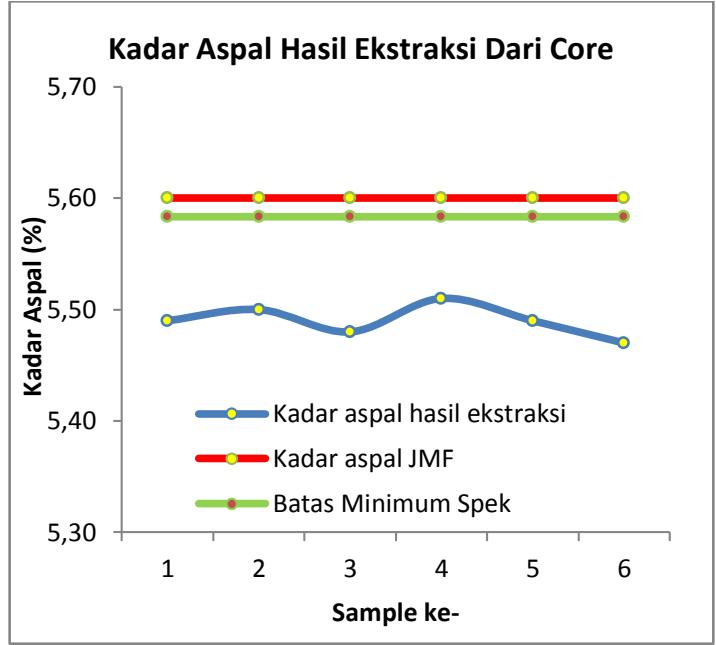

Gambar 6 Kurva kadar aspal saat di Belakang Asphalt Finisher

Dari Gambar 6 dapat dilihat bahwa kadar aspal hasil ekstraksi dari benda uji dari hasil core, ada yang nilainya di bawah dan di atas dari kadar aspal JMF 5,6\%, tetapi masih masuk dalam batas speksifikasi 2010 revisi 3 adalah $\pm 0,3 \%$, dengan nilai rata-rata $5,49 \%$.

Perbandingan hasil Pengujian Ekstraksi dari beberapa Benda Uji AMP, Finisher dan hasil Core drill dibandingkan dengan Job Mix Formula

Hasil rekapitulasi pengujian ekstraksi kadar aspal dengan menggunakan pelarut Bensin pada masing-masing benda uji, didapat bahwa nilai kadar aspal dari Core kecil dari finisher, dan kecil dari AMP. Untuk lebih jelas dapat dilihat pada Tabel 4.

Grafik kadar aspal hasil ekstraksi dari 6 (enam) sampel dari AMP dapat dilihat pada Gambar 7.
Tabel 4. Rekapitulasi pengujian ekstraksi kadar aspal

\begin{tabular}{|c|c|c|c|c|c|}
\hline \multirow[b]{2}{*}{ No } & \multirow{2}{*}{$\begin{array}{l}\text { Benda } \\
\text { Uji }\end{array}$} & \multicolumn{3}{|c|}{ Kadar Aspal Hasil Ekstraksi } & \multirow{2}{*}{$\begin{array}{l}\text { Kadar } \\
\text { Aspal } \\
\text { JMF } \\
(\%)\end{array}$} \\
\hline & & $\begin{array}{c}\text { AMP } \\
(\%) \\
\end{array}$ & $\begin{array}{c}\text { Finisher } \\
(\%) \\
\end{array}$ & $\begin{array}{l}\text { Core } \\
(\%) \\
\end{array}$ & \\
\hline 1 & $\begin{array}{l}\text { Sample } \\
-1\end{array}$ & 5.62 & 5.60 & 5.49 & 5.60 \\
\hline 2 & $\begin{array}{l}\text { Sample } \\
-2\end{array}$ & 5.58 & 5.58 & 5.50 & 5.60 \\
\hline 3 & $\begin{array}{l}\text { Sample } \\
-3\end{array}$ & 5.60 & 5.59 & 5.48 & 5.60 \\
\hline 4 & $\begin{array}{l}\text { Sample } \\
-4\end{array}$ & 5.61 & 5.56 & 5.51 & 5.60 \\
\hline 5 & $\begin{array}{l}\text { Sample } \\
-5\end{array}$ & 5.59 & 5.60 & 5.49 & 5.60 \\
\hline 6 & $\begin{array}{l}\text { Sample } \\
-6 \\
\end{array}$ & 5.60 & 5.55 & 5.47 & 5.60 \\
\hline \multicolumn{2}{|c|}{ Rata-rata } & 5.60 & 5.58 & 5.49 & 5.60 \\
\hline
\end{tabular}

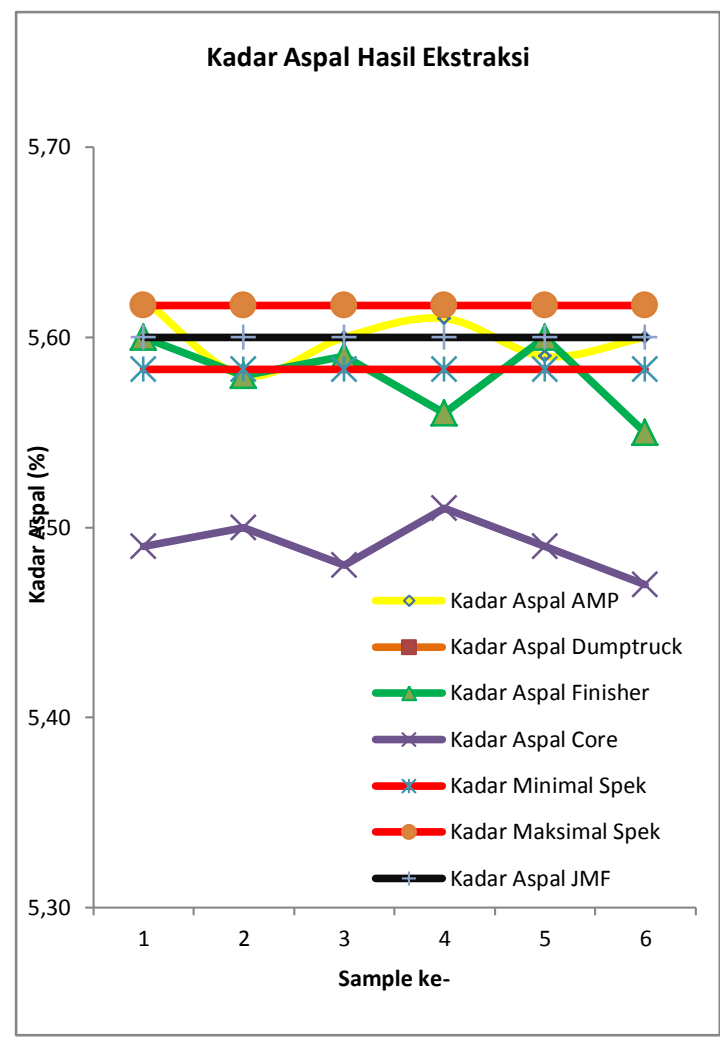

Gambar 7 Kurva kadar Kadar aspal hasil ekstraksi dari AMP, Asphalt Finisher dan Core 
Dari grafik diatas dapat diambil kesimpulan bahwa perbandingan kadar aspal hasil ekstraksi dengan menggunakan pertaline, dari pengujian ekstraksi kadar aspal Asphalt Mixing Plant (AMP), asphalt finisher dan hasil core drill nilai kadar aspalnya semakin berkurang, sehingga dapat dibuat rumusan kadar aspal (KA) hasil ekstraksi sebagai berikut :

$$
\begin{aligned}
& \text { KA Job mix Formula }(J M F) \\
& =\text { KA Asphalt Mixing Plant }(A M P) \\
& >\text { KA saat penghamparan }>\text { KA core } \\
& \text { Rata - rata }: \quad 5,60 \% \geqq 5,60 \% \\
& >5,58 \%>5,49 \%
\end{aligned}
$$

Nilai Kadar aspal AMP besar dan sama dengan JMF hal ini membuktikan bahwa kadar aspal yang dihasilkan oleh AMP sesuai dengan yang direncanakan. Namun Kadar aspal AMP lebih besar dari kadar aspal finisher dan core disebabkan karena aspal dari AMP merupakan aspal gembur yang baru selesai diolah dari AMP, sehingga pada saat dilakukan pengujian ekstraksi pengaruh kehilangan kadar aspal lebih kecil karena aspal belum meresap kedalam pori-pori agegat. Sedangkan pada saat penghamparan asphalt finisher kadar aspal yang didapat kecil dari AMP. Hal ini dapat diakibatkan proes pengakutan aspal dari AMP menuju lokasi, ditambah dengan pengaruh suhu di sekitarnya dan proses penghamparan dengan mesin penghampar (asphalt finisher) akibatnya aspal mulai meresap kedalam poripori agregat, sehingga hasil pengujian ekstraksi kadar aspal dari finisher kecil dari
AMP. Untuk sampel ekstraksi hasil core kadar aspal kecil dari AMP dan finisher, disebabkan lamanya jarak waktu pengambilan sampel dari waktu pelaksanaan penghamparan yang cukup lama yaitu 1 bulan . hal ini mengakibatkan aspal makin meresap kedalam pori-pori agregat. Agregat berpori berguna untuk menyerap aspal sehingga ikatan antara aspal dan agregat menjadi baik ( Sukirman, 2003). Ditambah dengan pengaruh suhu, penurunan suhu yang cepat adalah saat penghamparan bukan pada saat perjalanannya (Yusnita, 2012).

\section{KESIMPULAN DAN SARAN}

\section{Kesimpulan}

Dari penelitian dan pembahasan mengenai kadar aspal hasil ekstraksi penghamparan campuran aspal AC-BC dengan Job mix Formula, dapat diambil kesimpulan sebagai berikut:

Perbandingan kadar hasil ekstraksi dengan menggunakan pelarut pertalite, dari pengujian ekstraksi kadar aspal Asphalt Mixing Plant, Asphalt Finisher, Coredrill nilai aspal semakin berkurang dari JMF. Sehingga dapat dibuat rumusan KA Job mix Formula (JMF)

$$
\begin{gathered}
=K A \text { Asphalt Mixing Plant }(A M P) \\
>K A \text { saat penghamparan }>K A \text { core } \\
\text { Rata - rata }: \quad 5,60 \% \geqq 5,60 \% \\
>5,58 \%>5,49 \%
\end{gathered}
$$

hasil ekstraksi jauh dari ambang batas minimum toleransi campuran menurut spesifikasi Binamarga 2010 revisi 3(tiga). 
Maka dari itu penelitian ini juga dapat mendukung pernyataan pada spesifikasi Binamarga 2010 revisi 3(tiga) yang menyebutkan uji inti (core) tidak boleh digunakan untuk pengujian ekstraksi.

\section{Saran}

1. Diharapkan ada penelitian tentang kadar poriagregat sebelum dan sesudah ektraksi untuk campuran aspal AC-BC

2. Diharapkan ada peneliti selanjutnya menggunakan pelarut yang memiliki Oktan yang lebih tinggi agar hasil ekstraksi lebih teliti.

3. Disarankan untuk peneliti selanjutnya untuk mengkaji Stability (pengujian Marshall) Terhadap Campuran Aspal AC-BC.

\section{DAFTAR PUSTAKA}

Departemen Pemukiman dan Prasarana Wilayah. Manual Pekerjaan Campuran Beraspal Panas. Jakarta: Departemen Pemukiman dan Prasarana Wilayah direktorat jenderal prasarana wilayah.

Dinas Pekerjaan Umum. (2010). Spesifikasi Umum Binamarga 2010 Revisi 3. Jakarta: Dinas Pekerjaan Umum Bidang Binamarga.

Standar Nasional Indonesia. (2002). Metode Pengujian Kadar Aspal Dari Campuran Beraspal Dengan Cara Sentrifus. SNI 03-6894-2002

Standar Nasional Indonesia. (2002). Tata Cara Pengambilan Contoh
Agregat. SNI 03-6889-2002.

Riduwan. (2012). Metode dan Teknik Menyusun Tesis. Cetakan Pertama. Bandung: CV. Alfabeta.

Sukirman. (1999). Perkerasan Jalan Lentur. Jakarta: Nova.

Sukirman. (2003). Aspal Beton Campuran Panas. Jakarta: Granit.

Soehardi. F, Wiyono. S dan Wanim. A. (2014). Kajian Perbandingan Kadar Aspal Hasil Ekstraksi Campuran AC-WC Gradasi Kasar Dengan Cairan Ekstraksi Menggunakan Bensin. Pekanbaru: Program Magister Teknik Sipil Universitas Islam Riau.

Yusnita. (2012). Pengujian Pengaruh Penggunaan Batu Bara sebagai bahan bakar Asphalt Mixing Plant Pada CAmpuran AC-WC Aspal Curah dan Agregat Bangkinang. Pekanbaru: Program Magister Teknik Sipil Universitas Islam Riau. 